\title{
Editorial: The First Three Years (2013-2015) of Life: The Excitement of Biology
}

\author{
Jorge A. Santiago-Blay ${ }^{1}$
}

Herein I summarize the major developments in Life: The Excitement of Biology, emphasizing 2015. Below, I list some of our main accomplishments and, thereafter, I ponder about the roles of $\boldsymbol{L E B}$.

\section{Main Accomplishments}

1. Expanded Indexing, Referencing, and Availability. Life: The Excitement of Biology continues to be indexed and its published articles detected by Biosis, Biological Abstracts, CAB Abstracts, Google Scholar, and Research Gate. In 2015, LEB became available through the EBSCO Discovery Service (EDS) although not in full text. Also, Life: The Excitement of Biology is scheduled for inclusion in EBSCO's, Academic Search Ultimate (https://www.ebscohost.com/academic/academic-searchultimate), which is slated for release in September 2016. LEB continues participating fully in CitedBy (CrossRef, http://www.crossref.org/) and has a very good record of "resolutions", that is, correctly directing readers who click on the links to the correct publication. Wholehearted thanks to the staff members of CrossRef, for their help, particularly when I have made mistakes. Basch Subscriptions, a Prenax company (http://basch.com/bsi/, http://www.prenax.com/), as well as WT Cox Information Services (http://www.wtcox.com/), two subscription management companies headquartered in the USA, now include Life: The Excitement of Biology in their online platform databases.

2. Increased Internationalization. More scholars have joined the Board of Editors of Life: The Excitement of Biology during 2015. Currently, the board has nearly 100 members representing over 40 countries worldwide.

3. "Responsive" Presence via Social Media. Life: The Excitement of Biology continues having a strong digital presence through our digital carrier, WordPress. Its website, blaypublishers.com, is compatible with different types of mobile devices and screen sizes. The term used for this among website developers is "responsive", meaning that a web site follows responsive design principles. Also, $\boldsymbol{L E} \boldsymbol{B}$ maintains a regular presence,

\footnotetext{
${ }^{1} 217$ Wynwood Road, York, Pennsylvania 17402 USA. E-mail: blayjorge@ gmail.com
}

DOI: 10.9784/LEB4(1)SantiagoBlay.01

Electronically available on May 31, 2016. Mailed on May 31, 2016. 
particularly through Facebook, LinkedIn, and Twitter, Tumblr, among others.

4. Constantly Improving. Authors, reviewers, subscribers, and members of the boards of Life: The Excitement of Biology continue suggesting improvements to the journal many of which I have gratefully incorporated. This editor insists that all scientific papers submitted to $\boldsymbol{L E} \boldsymbol{B}$ be peer-reviewed while colleagues doing the evaluation of papers are encouraged to be fair, careful, contructive, and as fast as possible.

\section{Roles of Life: The Excitement of Biology in society at large}

In addition to serving as a peer-reviewed, international venue to the scientific community, I see a possible role for Life: The Excitement of Biology in society at large, through education. Nothing is more frustrating for people from all walks of life for whom life-long learning is in their hearts than trying to learn something and such learning be made difficult by a teacher who communicates in an unaccessible language. For instance, once, the unscientifically-trained wife of a colleague asked for a description of the chemical concept of mole. While her husband rapidly proceeded to define the term, including, yes, the $10^{23}$, as in a dictionary, I used simple language. Instead of the $10^{23}$ I said "a very large amount". The lady concluded the conversation by saying to her husband: "you speak to impress while Jorge speaks to communicate". That is exactly what Life: The Excitement of Biology aims: to communicate serious science in a language that more people understand.

All of these continue helping $\boldsymbol{L E B}$ gain visibility among the communities of scholars and the broader public. They could not have been possible without numerous fruitful communications with members of the board. The support of the Courtright Family of York, Pennsylvania (USA), owners of NeFra, printers of the hard copy version of Life: The Excitement of Biology as well as WordPress, carrier of the digital version of $\boldsymbol{L E B}$ and their friendly and helpful online staff members deserve a special recognition.

Please, feel free to spread the word about Life: The Excitement of Biology and its high quality, fast publication, and helpfulness; a great value, in sum, science for all. I hope all of you join me in a wonderful voyage of discovery during 2016.

Sincerely and gratefully,

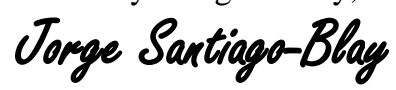

Jorge Santiago-Blay, Ph.D.

Editor-in-Chief, Life: The Excitement of Biology 